\title{
Serum parathyroid hormone levels in patients with chronic right heart failure
}

\author{
GANG-YONG WU ${ }^{1,2}$, QIN SHEN ${ }^{2}$, TING WU $^{2}$, YI-CHENG SHI $^{2}$, \\ TIAN-XIAO WANG ${ }^{2}$, GANG-JUN ZONG ${ }^{2}$ and XIANG-JUN YANG ${ }^{1}$
}

\author{
${ }^{1}$ Department of Cardiology, The First Affiliated Hospital of Soochow University, Suzhou, Jiangsu 215002; \\ ${ }^{2}$ Department of Cardiology, The 904th Hospital of the People's Liberation Army Joint Logistics Support Force, \\ Wuxi, Jiangsu 214044, P.R. China
}

Received June 16, 2019; Accepted November 22, 2019

DOI: $10.3892 /$ br.2019.1262

\begin{abstract}
Parathyroid hormone (PTH) is a novel cardiovascular biomarker which is particularly useful for detection and assessment of heart failure (HF). However, previous studies examining PTH in heart failure have primarily focused on left HF; thus, the relationship between PTH and right HF remains unclear. The aim of the present study was to evaluate the serum PTH levels in patients with chronic right HF. A total of 154 patients with chronic right HF were enrolled in the present study. A binary logistic regression analysis model was used to assess the independent predictive value of PTH levels in chronic right HF. Partial correlative analysis was used to demonstrate the relevance of PTH levels on the parameters of assessment of right heart function. A multiple linear regression analysis model was used to evaluate the independent factors of PTH levels in patients with right HF. The results showed that the serum PTH levels in the right HF group were significantly higher compared with the control group. After adjusting for predictors of right HF, serum PTH levels were associated with right $\mathrm{HF}$ with an odds ratio of 1.066 (95\% confidence interval: 1.030-1.102, P $<0.001$. Serum PTH levels were independently correlated with plasma $\mathrm{N}$-terminal pro-B-type natriuretic peptide levels, right ventricular end-diastolic diameter and severity of lower extremity edema (all $\mathrm{P}<0.05$ ). Therefore, based on the results of the present study, PTH may be a useful biomarker for detection and assessment of right HF.
\end{abstract}

\section{Introduction}

Right heart failure (HF) is a clinical syndrome caused by right ventricular systolic and/or diastolic dysfunction (1). Previous

Correspondence to: Dr Xiang-Jun Yang, Department of Cardiology, The First Affiliated Hospital of Soochow University, 188 Shizi Street, Suzhou, Jiangsu 215002, P.R. China

E-mail: 1354920456@qq.com

Key words: parathyroid hormone, right heart failure, N-terminal pro-B-type natriuretic peptide, right ventricle, tricuspid regurgitation studies have primarily focused on function of the left heart, thus our current understanding of right HF stems from that of left HF (2-4). However, right HF is becoming an increasingly common symptom of cardiovascular disease, with morbidity and case fatality rates exceeding those associated with left HF (5). Right HF is also an independent prognostic factor for left HF (6). Therefore, the timely identification of right $\mathrm{HF}$ is important; however, early clinical presentation of right $\mathrm{HF}$ is nonspecific, and due to the irregularity and uncertainty of the shape of the right ventricle, there are no unified measurement methods or exemplar data at present, which limits the application of echocardiography (7). The identification of biomarkers associated with specific diseases has become a prominent research topic recently (8-11). B-type natriuretic peptide (BNP) and N-terminal pro-BNP (NT-proBNP) levels are closely associated with right cardiac insufficiency, reflecting the severity of the disease, curative effect, survival, hemodynamic changes and prognosis of patients with right HF (12-15). Additionally, troponin, endothelin-1, d-dimer, C-reactive protein (CRP) and bilirubin levels also reflect myocardial damage, hemodynamic status, or severity of the disease in patients with right HF (16-20). However, all these results are derived from studies with small sample sizes, and some conclusions are inconsistent (21). Studies have shown that parathyroid hormone (PTH) is a cardiovascular biomarker which is closely associated with various diseases including arteriosclerosis, hypertension, left ventricular hypertrophy, and coronary artery and valvular calcification, and it as an independent predictor of HF (22-29). However, as the existing studies did not distinguish between left and right $\mathrm{HF}$, the association between PTH levels and right HF remains unclear. Theoretically, in right HF, the contractility of the right ventricle has been compromised, leading to dilation of capacitance vessels and decline in effective circulating blood volume (30). Consequently, the kidneys are under perfused, leading to the release of renin. Aldosteronism is the result of hormonal system activation and usually accompanied by marked excretory wasting of calcium and magnesium in both feces and urine, leading to ionized hypocalcemia and hypomagnesemia (31-34). In turn, the calcium-sensing receptor of the parathyroid glands are activated to increase the secretion of PTH (35). Additionally, right ventricular capacity and pressure load increase, whereas coronary artery perfusion pressure 
decreases, leading to myocardial ischemia (36). Chronically increased right ventricular pressure can lead to increased pulmonary artery pressure, potentially affecting blood oxygen exchange, which may be followed by myocardial hypoxia (37). Meyer et al (38) suggested that myocardial ischemic hypoxia and pressure load may result in increased serum PTH levels. Therefore, the aim of the present study was to evaluate serum PTH levels in patients with chronic right HF and determine its diagnostic value for assessment and detection of right HF in patients.

\section{Patients and methods}

Patients. As the present study was a retrospective analysis of anonymized patient data, ethical approval was not required. The clinical data from 925 patients with HF who were treated at the 904th Hospital of the People's Liberation Army Joint Logistics Support Force (Wuxi, China) between January 2015 and December 2016 were retrospectively analyzed. Diagnosis of HF was based on the 2007 China Guidelines for the Diagnosis and Treatment of Chronic Heart Failure (39), and the plasma NT-proBNP levels in these patients were all $>400 \mathrm{pg} / \mathrm{ml}$. Patients with common heart problems, including coronary heart disease, hypertension, pulmonary hypertension, cardiomyopathy, heart valvular disease and chronic obstructive pulmonary disease, were included in the present study, whereas patients with rheumatic heart disease and chronic constrictive pericarditis were excluded. Patients with acute conditions, such as acute pulmonary embolism, myocardial infarction, myocarditis and pericarditis, were also excluded. The diagnostic criteria of right HF were based on the 2012 consensus of Chinese experts on the diagnosis and treatment of right HF (5), and specifically includes: i) possible cause of right HF; ii) symptoms and signs of right HF; and iii) objective evidence of abnormal right ventricular structure and/or function and increased intracardiac pressure. Patients with left ventricular ejection fraction (LVEF) $<50 \%$, thickening of the left ventricular wall and decreased left ventricular compliance were excluded as the ratio of the maximum ventricular filling speed in early diastole to that in late diastole is $<1$. Additionally, patients with serum creatinine level $\geq 265 \mu \mathrm{mol} / \mathrm{l}$ or a history of thyroid disease, primary hyperparathyroidism, skeletal diseases, chronic malnutrition or any malignancy were excluded. Based on these inclusion and exclusion criteria, a total of 154 patients consisting of 60 men and 94 women, with a mean age \pm standard deviation of $75.64 \pm 9.78$ years (range 36-96 years) were analyzed in the present study. The control group consisted of 56 patients consisting of 31 men and 25 women, with a mean age \pm standard deviation of $61.75 \pm 15.23$ (range 26-88 years) without HF who were admitted to the same hospital during the same time period. In the control group, NT-proBNP levels were all $<100 \mathrm{pg} / \mathrm{ml}$, echocardiographic data were normal, and none of the patients exhibited any of aforementioned exclusion criteria.

In this retrospective and observational study, 30 patients with right HF and 20 patients without HF were chosen at random, and the mean and standard deviation of PTH in the two groups were obtained, and differences between the groups were compared using an independent samples t-test using MedSci software (Version 4.8.1; Shanghai Chungu Biomedical
Table I. Clinical features of patients in both groups.

\begin{tabular}{|c|c|c|c|c|}
\hline Groups & $\begin{array}{l}\text { Control } \\
\text { group, } \mathrm{n}\end{array}$ & $\begin{array}{c}\mathrm{HF} \\
\text { group, } \mathrm{n}\end{array}$ & $\chi^{2}$-value & P-value \\
\hline Sex & & & 4.496 & $0.034^{\mathrm{a}}$ \\
\hline Male & 31 & 60 & & \\
\hline Female & 25 & 94 & & \\
\hline $\begin{array}{l}\text { Coronary artery } \\
\text { disease }\end{array}$ & & & 8.353 & $0.004^{\mathrm{b}}$ \\
\hline Yes & 22 & 95 & & \\
\hline No & 34 & 59 & & \\
\hline Hypertension & & & 0.731 & 0.393 \\
\hline Yes & 45 & 115 & & \\
\hline No & 11 & 36 & & \\
\hline Diabetes & & & 0.215 & 0.643 \\
\hline Yes & 11 & 26 & & \\
\hline No & 45 & 125 & & \\
\hline Hyperlipemia & & & 7.717 & $0.005^{\mathrm{b}}$ \\
\hline Yes & 4 & 0 & & \\
\hline No & 52 & 154 & & \\
\hline Smoker & & & 2.549 & 0.110 \\
\hline Yes & 9 & 13 & & \\
\hline No & 47 & 141 & & \\
\hline Alcohol consumption & & & 1.469 & 0.226 \\
\hline Yes & 6 & 9 & & \\
\hline No & 50 & 145 & & \\
\hline Valvular heart disease & & & 13.225 & $<0.001^{\circ}$ \\
\hline Yes & 0 & 31 & & \\
\hline No & 56 & 123 & & \\
\hline Cardiomyopathy & & & 0.418 & 0.518 \\
\hline Yes & 0 & 4 & & \\
\hline No & 56 & 150 & & \\
\hline Atrial fibrillation & & & 31.358 & $<0.001^{\mathrm{c}}$ \\
\hline Yes & 6 & 83 & & \\
\hline No & 50 & 71 & & \\
\hline
\end{tabular}

${ }^{\mathrm{a}} \mathrm{P}<0.05,{ }^{\mathrm{b}} \mathrm{P}<0.01,{ }^{\mathrm{c}} \mathrm{P}<0.001 . \mathrm{HF}$, heart failure.

Technology, Co., Ltd.). The mean values of two independent samples were compared, with an $\alpha$ level of 0.05 (two-tailed) and a test efficacy of $0.80(1-\beta, \beta=0.2)$, the ratio of sample size between the right HF group and the control group was 1.5, and a two-sided test was used, and based on this, the required sample size was calculated. The results of this analysis showed that the number of samples included in our study fully met the statistical requirements.

Methods. General information: Patient data regarding coronary artery disease, diabetes, hypertension, hyperlipidemia, as well as history of alcohol and smoking consumption were collected, and patients were stratified according to their status in each group. Patients were classified as smokers if they had smoked $\geq 100$ cigarettes in their life (40), and alcohol 
Table II. Clinical and biochemical parameters.

\begin{tabular}{|c|c|c|c|c|}
\hline $\begin{array}{l}\text { Clinicopathological } \\
\text { characteristics }\end{array}$ & $\begin{array}{c}\text { Control group, } \\
\text { mean } \pm \text { standard deviation }\end{array}$ & $\begin{array}{c}\text { HF group, } \\
\text { mean } \pm \text { standard deviation }\end{array}$ & $\mathrm{t}$ & P-value \\
\hline Age, years & $61.75 \pm 15.23$ & $75.64 \pm 9.78$ & -6.364 & $<0.001^{\mathrm{b}}$ \\
\hline BMI, $\mathrm{kg} / \mathrm{m}^{2}$ & $24.64 \pm 3.76$ & $23.02 \pm 4.01$ & 2.628 & $0.009^{\mathrm{a}}$ \\
\hline PTH, pg/ml & $33.32 \pm 13.93$ & $83.72 \pm 53.65$ & -10.708 & $0.000^{\mathrm{b}}$ \\
\hline NT-proBNP, pg/ml & - & $3,684.81 \pm 5,272.20$ & - & - \\
\hline Albumin, $\mathrm{g} / \mathrm{l}$ & $40.29 \pm 3.44$ & $37.86 \pm 4.28$ & 3.814 & $<0.001^{\mathrm{b}}$ \\
\hline $\mathrm{TC}(\mathrm{mmol} / \mathrm{l})$ & $4.15 \pm 1.07$ & $3.95 \pm 1.10$ & -0.553 & 0.581 \\
\hline LDL-C (mmol/l) & $1.92 \pm 0.71$ & $1.33 \pm 0.54$ & 5.655 & $<0.001^{\mathrm{b}}$ \\
\hline HDL-C (mmol/l) & $1.30 \pm 0.84$ & $1.15 \pm 0.59$ & 1.458 & 0.146 \\
\hline $\mathrm{TG}(\mathrm{mmol} / \mathrm{l})$ & $2.04 \pm 1.79$ & $1.87 \pm 1.17$ & 0.801 & 0.424 \\
\hline CRP (mg/l) & $3.00 \pm 3.76$ & $11.76 \pm 25.93$ & -4.074 & $<0.001^{\mathrm{b}}$ \\
\hline Troponin (pg/ml) & $0.01 \pm 0.00$ & $0.07 \pm 0.18$ & -4.015 & $<0.001^{\mathrm{b}}$ \\
\hline $\operatorname{GFR}\left(\mathrm{ml} / \mathrm{min} / 1.73 \mathrm{~m}^{2}\right)$ & $91.42 \pm 34.22$ & $61.21 \pm 28.58$ & 6.414 & $<0.001^{\mathrm{b}}$ \\
\hline Corrected calcium (mmol/l) & $2.35 \pm 0.16$ & $2.25 \pm 0.18$ & 3.713 & $<0.001^{\mathrm{b}}$ \\
\hline Inorganic phosphate $(\mathrm{mmol} / \mathrm{l})$ & $1.13 \pm 0.16$ & $1.12 \pm 0.32$ & 0.295 & 0.769 \\
\hline Magnesium (mmol/l) & $0.78 \pm 0.09$ & $0.78 \pm 0.20$ & -0.021 & 0.983 \\
\hline $\mathrm{FBG}(\mathrm{mmol} / \mathrm{l})$ & $5.47 \pm 1.75$ & $5.56 \pm 1.88$ & -0.300 & 0.765 \\
\hline $\mathrm{TB}(\mathrm{mmol} / \mathrm{l})$ & $13.35 \pm 7.46$ & $21.41 \pm 16.28$ & -4.890 & $<0.001^{\mathrm{b}}$ \\
\hline $\mathrm{CB}(\mathrm{mmol} / \mathrm{l})$ & $3.75 \pm 2.92$ & $8.36 \pm 8.65$ & -5.778 & $<0.001^{\mathrm{b}}$ \\
\hline $\mathrm{UCB}(\mathrm{mmol} / \mathrm{l})$ & $9.63 \pm 4.85$ & $12.86 \pm 9.29$ & -3.268 & $0.001^{\mathrm{a}}$ \\
\hline $\mathrm{LAD}(\mathrm{mm})$ & $34.86 \pm 4.70$ & $42.60 \pm 9.05$ & -8.037 & $<0.001^{\mathrm{b}}$ \\
\hline LVEDD (mm) & $45.44 \pm 4.52$ & $46.93 \pm 5.37$ & -1.852 & 0.066 \\
\hline $\operatorname{RAD}(\mathrm{mm})$ & $31.11 \pm 2.88$ & $39.40 \pm 8.57$ & -10.481 & $<0.001^{\mathrm{b}}$ \\
\hline RVEDD (mm) & $20.36 \pm 3.85$ & $28.69 \pm 7.81$ & -10.246 & $<0.001^{\mathrm{b}}$ \\
\hline $\operatorname{PAD}(\mathrm{mm})$ & $19.70 \pm 1.55$ & $21.63 \pm 3.19$ & -5.857 & $<0.001^{\mathrm{b}}$ \\
\hline LVEF, \% & $61.55 \pm 2.71$ & $58.45 \pm 3.98$ & 6.405 & $<0.001^{\mathrm{b}}$ \\
\hline MR (ml) & $0.31 \pm 0.88$ & $4.76 \pm 8.41$ & -6.460 & $<0.001^{\mathrm{b}}$ \\
\hline $\mathrm{TR}(\mathrm{ml})$ & $0.26 \pm 0.79$ & $8.31 \pm 11.91$ & -8.330 & $<0.001^{\mathrm{b}}$ \\
\hline $\mathrm{AR}(\mathrm{ml})$ & $0.26 \pm 0.76$ & $1.60 \pm 2.81$ & -5.373 & $<0.001^{\mathrm{b}}$ \\
\hline PR (ml) & $0.24 \pm 0.60$ & $1.05 \pm 2.49$ & -3.751 & $<0.001^{\mathrm{b}}$ \\
\hline
\end{tabular}

${ }^{\mathrm{a}} \mathrm{P}<0.01,{ }^{\mathrm{b}} \mathrm{P}<0.001$. BMI, body mass index; $\mathrm{PTH}$, parathyroid hormone; NT-proBNP, N-terminal pro-B-type natriuretic peptide; TC, total cholesterol; LDL-C, low-density lipoprotein cholesterol; HDL-C, high-density lipoprotein cholesterol; TG, triglyceride; CRP, C-reactive protein; GFR, glomerular filtration rate; FBG, fasting blood glucose; TB, total bilirubin; CB, direct bilirubin; UCB, indirect bilirubin; LAD, left atrial diameter; LVEDD, left ventricular end-diastolic diameter; RAD, right atrial diameter; RVEDD, right ventricular end-diastolic diameter; PAD, pulmonary artery diameter; LVEF, left ventricular ejection fraction; MR, mitral regurgitation; TR, tricuspid regurgitation; AR, aortic regurgitation; PR, pulmonary regurgitation; HF, heart failure.

consumption was defined as the consumption of any alcoholic beverage, including white wine, beer, fruit wine, yellow rice wine or any other alcoholic drinks (41). Body mass index (BMI) was calculated based on the body weight and height. Fasting venous blood $(3 \mathrm{ml})$ was drawn on the day of admission or the following day to measure the levels of albumin, creatinine, electrolytes, total cholesterol (TC), low-density lipoprotein cholesterol, high-density lipoprotein cholesterol (HDL-C), triglycerides (TG), fasting blood glucose (FBG), total bilirubin (TB), direct bilirubin (CB), indirect bilirubin (UCB) and CRP using an automatic biochemical analyzer (Olympus Corporation).

Cardiac function and edema grade evaluation at admission: Patients' heart function was evaluated according to the
New York Heart Association (NYHA) Cardiac Function Classification Standard when they were first admitted to the hospital (42), and any liver jugular vein reflux was recorded. The severity of edema was evaluated whilst the patient was standing. The degree of edema was classified as follows: Below the ankle, first-degree edema; below the knee, second-degree edema; below the hip, third-degree edema; and on the hip, fourth-degree edema.

Venous blood samples were collected immediately following admission. Serum PTH levels were detected using an ELISA kit (cat. no. 989731; Beckman Coulter, Inc.). The normal range of PTH levels is $14-72 \mathrm{pg} / \mathrm{ml}$. Plasma NT-proBNP levels were also measured immediately following admission using a colloidal gold method according to the manufacturer's 
Table III. Binary logistic regression analysis of independent predictors of right HF.

\begin{tabular}{lccrrr}
\hline Indicators & $\beta$ & Wald value & P-value & OR & 95\% CI \\
\hline Age & 0.048 & 4.499 & $0.034^{\mathrm{a}}$ & 1.049 & $1.004-1.097$ \\
NYHA & 0.689 & 4.663 & $0.031^{\mathrm{a}}$ & 1.992 & $1.066-3.723$ \\
PTH & 0.063 & 13.610 & $<0.001^{\mathrm{b}}$ & 1.066 & $1.030-1.102$ \\
TR & 0.491 & 5.705 & $0.017^{\mathrm{a}}$ & 1.634 & $1.092-2.445$ \\
\hline
\end{tabular}

${ }^{\mathrm{a}} \mathrm{P}<0.05,{ }^{\mathrm{b}} \mathrm{P}<0.001$. HF, heart failure; NYHA, New York Heart Association heart function grade; PTH, parathyroid hormone; TR, tricuspid regurgitation; OR, odds ratio; $\mathrm{CI}$, confidence interval.

protocol (NT-proBNP detection kits, cat. no. 7273690; Getein Biotechnology Co., Ltd.), which is able to measure levels within a range of $100-30,000 \mathrm{pg} / \mathrm{ml}$.

The estimated glomerular filtration rate (eGFR) was calculated using the formula eGFR $\left(\mathrm{ml} \cdot \mathrm{min}^{-1}\right.$ per $\left.1.73 \mathrm{~m}^{2}\right)=(140$-age $)$ $\mathrm{x}$ weight $/ 0.818 \mathrm{x}$ creatinine level $(\mu \mathrm{mol} / \mathrm{l})$ and was multiplied by 0.85 in female patients (43).

All patients underwent Doppler ultrasound examination of the heart using color Doppler echocardiography (Vivid E9; GE Healthcare) within $48 \mathrm{~h}$ of admission. During this examination, the diameters of the left and right atria, left and right ventricular diastolic diameters, pulmonary artery diameter, valve return flow and left ventricular ejection fraction were measured. The proximal isokinetic surface area method was used to quantitatively evaluate the degree of valve regurgitation (44), and for patients with an irregular regurgitation orifice area, the effective regurgitation orifice area was automatically calculated by the apparatus and the regurgitation velocity time integral was multiplied to directly evaluate the degree of regurgitation. In patients with atrial fibrillation (AF) or arrhythmia, at least 5 representative images were collected from each patient for comprehensive evaluation.

Therapeutic regimen: In patients with no contraindications, angiotensin-converting enzyme inhibitors (ACEIs) and $\beta$-blockers were administered. Angiotensin receptor blockers were used in patients with a dry cough and those who could not tolerate ACEIs. Prior to admission, diuretics and aldosterone receptor antagonists were administered based on whether patients had any contra-indications to these.

Statistical analysis. Quantitative data are presented as the mean \pm standard deviation, and analysis of normal distribution was performed using a Shapiro-Wilk test. Additionally, a homogeneity-of-variance test was used and if equal variances were assumed, differences were analyzed using a Student's t-test, otherwise, differences were analyzed using a Welch's t-test. Qualitative data are presented as the frequency and percentage, and differences were calculated using a $\chi^{2}$ test. Independent predictors of right $\mathrm{HF}$ between the two groups were identified using binary logistic regression analysis. In the right HF group, correlations between PTH levels and other indicators were determined using partial correlation analysis, and the independent factors of increased PTH levels were further determined using multiple linear regression analysis. All $\mathrm{P}$-values are two-sided and $\mathrm{P}<0.05$ was considered to indicate a statistically significant difference.
Table IV. Partial correlation analysis of PTH levels with other indicators of right $\mathrm{HF}$.

\begin{tabular}{lcc}
\hline Indicators & $\mathrm{r}$ & P-value \\
\hline NT-proBNP & 0.245 & $0.001^{\mathrm{b}}$ \\
GFR & -0.145 & $0.036^{\mathrm{a}}$ \\
RVEDD & 0.285 & $0.001^{\mathrm{b}}$ \\
LED & 0.224 & $0.010^{\mathrm{a}}$ \\
TR & 0.199 & $0.014^{\mathrm{a}}$
\end{tabular}

${ }^{\mathrm{a}} \mathrm{P}<0.05,{ }^{\mathrm{b}} \mathrm{P}<0.01$. $\mathrm{PTH}$, parathyroid hormone; HF, heart failure; NT-proBNP, N-terminal pro-B-type natriuretic peptide; GFR, glomerular filtration rate; RVEDD, right ventricular end-diastolic diameter; LED, lower extremity edema; TR, tricuspid regurgitation.

Statistical analysis was performed using SPSS version 13.0 (SPSS, Inc.).

\section{Results}

Clinical indicators of right HF. A total of 154 patients with right $\mathrm{HF}$ were enrolled in this study, and the average serum PTH level was $83.72 \pm 53.65 \mathrm{pg} / \mathrm{ml}$ (range, 19.8-328). The control group consisted of 56 individuals who had an average serum PTH level of $33.32 \pm 13.93 \mathrm{pg} / \mathrm{ml}$ (range, 11.1-71.2). Between-group comparisons showed that the values of all indicators, including PTH, were significantly different between the two groups, with the exceptions of inorganic phosphate, magnesium, FBG, TG, TC, HDL-C and left ventricular internal diameter (all $\mathrm{P}<0.05$; Tables I and II).

Independent predictive value of indicators of right $H F$. As NT-proBNP levels represent one of the diagnostic criteria for right $\mathrm{HF}$, it was excluded, and the remaining indices that were significantly different between the two groups were included in a binary logistic regression analysis to identify independent predictors of right HF. This analysis revealed that age, NYHA heart function grade, PTH levels and tricuspid valve reverse flow were predictors of right $\mathrm{HF}$, with odds ratios of 1.049 [95\% confidence interval (CI): 1.004-1.097], 1.992 (95\% CI: 1.066-3.723), 1.066 (95\% CI: 1.030-1.102) and 1.634 (95\% CI: 1.092-2.445), respectively (all $\mathrm{P}<0.05$; Table III). Together, these results confirmed that PTH levels are independently associated with right HF. 
Table V. Multiple linear regression analysis for independent factors of PTH levels.

\begin{tabular}{lcccc}
\hline Indicators & $\beta$ & $\mathrm{t}$ & P-value & $95 \%$ CI \\
\hline NT-proBNP & 0.002 & 2.901 & $0.004^{\mathrm{b}}$ & $0.001-0.003$ \\
GFR & -0.259 & -2.255 & $0.026^{\mathrm{a}}$ & $-0.486--0.032$ \\
Troponin & 82.302 & 4.530 & $<0.001^{\mathrm{c}}$ & $46.390-118.215$ \\
RVEDD & 2.092 & 3.587 & $<0.00^{\mathrm{c}}$ & $0.939-3.245$ \\
LED & 13.413 & 3.544 & $0.001^{\mathrm{b}}$ & $5.933-20.892$
\end{tabular}

${ }^{\mathrm{a}} \mathrm{P}<0.05,{ }^{\mathrm{b}} \mathrm{P}<0.01,{ }^{\mathrm{c}} \mathrm{P}<0.001$. $\mathrm{PTH}$, parathyroid hormone; HF, heart failure; NT-proBNP, N-terminal pro-B-type natriuretic peptide; GFR, glomerular filtration rate; RVEDD, right ventricular end-diastolic diameter; LED, lower extremity edema.

Correlation of PTH levels with other indicators of right HF. In the right HF group, correlations of PTH levels with other indicators were determined using a partial correlation analysis, and the results indicated that PTH levels were associated with NT-proBNP levels, eGFR, right ventricular diameter, tricuspid valve flow and the degree of lower extremity edema, with partial correlation coefficients of $0.245,-0.145,0.285,0.224$ and 0.199, respectively (all $\mathrm{P}<0.05$; Table IV). Increased PTH levels were associated with higher NT-proBNP levels, larger right ventricular diameter, greater tricuspid valve reverse flow, greater severity of lower extremity edema and lower eGFR.

Independent factors associated with PTH levels. Sex, age, BMI, eGFR; TB, CB, UCB, albumin, PTH and NT-proBNP levels; heart chamber size, pulmonary artery diameter, valve return flow rate and the degree of lower extremity edema were measured using multiple linear regression analysis. The results showed that PTH levels were independently associated with NT-proBNP levels, eGFR, troponin levels, right ventricular diameter and the degree of lower extremity edema (all $\mathrm{P}<0.05$; Table V). Further analysis confirmed that PTH levels were closely associated with right cardiac function indices, including NT-proBNP levels, right ventricular diameter and the degree of lower extremity edema.

\section{Discussion}

There an increasing number of studies demonstrating that PTH serves an important role in the development and progression of cardiovascular diseases, particularly in HF. PTH can independently predict the incidence of non-ischemic and whole HF (45), improve the risk stratification of patients with $\mathrm{HF}$ and assist in the determination of the optimal hospitalization time for outpatients with HF (46). It may also be used to guide individualized treatment of $\mathrm{HF}$ (47). However, previous studies have not examined the correlation between PTH levels with right $\mathrm{HF}$ specifically.

In the present study, indicators of right heart function, including clinical indications, biochemical indices and cardiac ultrasound results were used to determine the prognostic value of PTH in patients with right HF by analyzing the correlation between serum PTH levels with the aforementioned indices. According to the comparisons between the control and experimental groups, serum PTH levels were increased in patients with right HF compared with the controls. Although age, sex and LVEF were different between the two groups, and PTH release increases with age and left $\operatorname{HF}(27,29)$, the results of the binary logistic regression analysis further confirmed that PTH levels was an independent predictor of right HF. In the right HF group, the serum PTH levels increased with increased NT-proBNP levels, right ventricular diameter, tricuspid valve reverse flow and the degree of lower extremity edema, with statistically significant partial correlations. The multiple linear regression analysis results further confirmed that PTH was independently associated with the aforementioned indicators apart from tricuspid regurgitation. Thus, tricuspid regurgitation may not be an independent risk factor which is related to other factors. These results demonstrate the correlation between serum PTH levels with right heart function, indicating that this marker may accurately reflect right $\mathrm{HF}$ with good sensitivity.

Additionally, the rates of hypertension, diabetes, cardiomyopathy, smoking and alcohol consumption did not differ between the two groups. Some of these findings may due to the fact that hypertension primarily affects the left ventricular afterload, thus primarily involves left heart function (48). Additionally, the low incidence of patients with cardiomyopathy in the cohort, and in particular right ventricular cardiomyopathy, may explain why no significant difference was observed between the two groups. It has been reported that PTH is involved in the occurrence of various arrhythmias (49). In the present study, the PTH levels and the rate of $\mathrm{AF}$ in the right HF group were significantly higher compared with the control group, which supports the correlation between PTH levels and arrhythmia. However, the results of partial correlation analysis showed that AF was not correlated with PTH levels in the right HF group, and this may be because AF has more influence on left cardiac function (50). The results also showed that troponin, CRP, TB, CB and UCB levels were higher in the right HF group compared with the control group, and these findings were associated with myocardial injury, inflammation, increased venous pressure and extravasated blood in the liver during HF. All these findings support the results of previous studies $(16,18)$.

The present study has some limitations. When selecting research subjects, only patients with left $\mathrm{HF}$ who had decreased ejection fraction and/or declined left ventricular compliance were excluded, but patients with left atrial enlargement and/or AF were included, among whom, there was no strict classification of HF etiology. As a result, patients with coronary heart 
disease, cardiomyopathy and pulmonary hypertension were enrolled. Additionally, as this was a retrospective analysis, the echocardiographic results lack some of the more reliable measurements that have become available, such as tricuspid annular shortening rate and right ventricular ejection fraction; and the inner diameter rather than the volume was used when measuring the size of the atria and ventricles. To avoid additional trauma, the hospitalized patients did not undergo regular right heart angiography; therefore, more objective and accurate evaluation indices of right heart function, such as central venous pressure, right ventricular pressure and pulmonary artery pressure were not recorded. The present study serves as a preliminary analysis of the relationship between PTH levels and clinical indices of right HF. The conclusions made within, provide a starting point for future research, which should include determination of the role and underlying mechanisms of serum PTH levels in right HF.

In conclusion, the serum PTH levels are correlated with right $\mathrm{HF}$, and thus may be used for the clinical assessment of right heart function.

\section{Acknowledgements}

Not applicable.

\section{Funding}

This study was supported by the Scientific Research Project of the Wuxi Municipal Health and Family Planning Commission (Wuxi, China; grant no. MS201638).

\section{Availability of data and materials}

The datasets used and/or analyzed during the present study are available from the corresponding author on reasonable request.

\section{Authors' contributions}

GW and XY conceived and designed the study. GW, QS, TW, YS, TW and GZ performed the experiments. GW, GZ and XY performed the data analysis. GW drafted the manuscript. All authors read and approved the final manuscript.

\section{Ethics approval and consent to participate}

The present study was a retrospective analysis of anonymized patient data, thus ethical approval was not required.

\section{Patient consent for publication}

Not applicable.

\section{Competing interests}

The authors declare that they have no competing interests.

\section{References}

1. Melenovsky V, Hwang SJ, Lin G, Redfield MM and Borlaug BA Right heart dysfunction in heart failure with preserved ejection fraction. Eur Heart J 35: 3452-3462, 2014.
2. Haddad F, Doyle R, Murphy DJ and Hunt SA: Right ventricular function in cardiovascular disease, part II: Pathophysiology, clinical importance, and management of right ventricular failure. Circulation 117: 1717-1731, 2008

3. Zhang CY, Li XH, Zhang T, Fu J and Cui XD: Hydrogen sulfide upregulates heme oxygenase-1 expression in rats with volume overload-induced heart failure. Biomed Rep 1: 454-458, 2013.

4. Sedmera D, Neckar J, Benes J Jr, Pospisilova J, Petrak J, Sedlacek K and Melenovsky V: Changes in Myocardial Composition and Conduction Properties in Rat Heart Failure Model Induced by Chronic Volume Overload. Front Physiol 7: 367, 2016.

5. Editorial Board of Chinese Journal of Cardiology, Chinese Society of Cardiology: Consensus of Chinese experts on diagnosis and treatment of right heart failure. Chin J Cardiol 40: 449-461, 2012.

6. Adegunsoye A, Levy M and Oyenuga O: Novel Therapeutic Strategies for Reducing Right Heart Failure Associated Mortality in Fibrotic Lung Diseases. BioMed Res Int 2015: 929170, 2015.

7. Chua S, Levine RA, Yosefy C, Handschumacher MD, Chu J, Qureshi A, Neary J, Ton-Nu TT, Fu M, Wu CJ, et al: Assessment of right ventricular function by real-time three-dimensional echocardiography improves accuracy and decreases interobserver variability compared with conventional two-dimensional views. Eur J Echocardiogr 10: 619-624, 2009.

8. Meijers WC, van der Velde AR, Muller Kobold AC, Dijck-Brouwer J, Wu AH, Jaffe A and de Boer RA: Variability of biomarkers in patients with chronic heart failure and healthy controls. Eur J Heart Fail 19: 357-365, 2017.

9. Welsh P, Kou L, Yu C, Anand I, van Veldhuisen DJ, Maggioni AP, Desai AS, Solomon SD, Pfeffer MA, Cheng S, et al: Prognostic importance of emerging cardiac, inflammatory, and renal biomarkers in chronic heart failure patients with reduced ejection fraction and anaemia: RED-HF study. Eur J Heart Fail 20: 268-277, 2018.

10. Du W, Piek A, Schouten EM, van de Kolk CWA, Mueller C, Mebazaa A, Voors AA, de Boer RA and Silljé HHW: Plasma levels of heart failure biomarkers are primarily a reflection of extracardiac production. Theranostics 8: 4155-4169, 2018.

11. Ahmad T, Fiuzat M, Pencina MJ, Geller NL, Zannad F, Cleland JG, Snider JV, Blankenberg S, Adams KF, Redberg RF, et al: Charting a roadmap for heart failure biomarker studies. JACC Heart Fail 2: 477-488, 2014.

12. Malfatto G, Della Rosa F, Rella V, Villani A, Branzi G, Blengino S, Giglio A, Facchini M and Parati G: Prognostic value of noninvasive hemodynamic evaluation of the acute effect of levosimendan in advanced heart failure. J Cardiovasc Med (Hagerstown) 15: 322-330, 2014.

13. Agoston-Coldea L, Lupu S, Hicea S, Paradis A and Mocan T: Serum levels of the soluble IL-1 receptor family member ST2 and right ventricular dysfunction. Biomarkers Med 8: 95-106, 2014.

14. Pasha SM, Klok FA, van der Bijl N, de Roos A, Kroft LJM and Huisman MV: NT-pro-BNP levels in patients with acute pulmonary embolism are correlated to right but not left ventricular volume and function. Thromb Haemost 108: 367-372, 2012.

15. Wang Y, Liu ZH, Zhang HL, Luo Q, Zhao ZH and Zhao Q: Association of elevated NTproBNP with recurrent thromboembolic events after acute pulmonary embolism. Thromb Res 129: 688-692, 2012

16. Gomez-Arroyo J, Sandoval J, Simon MA, Dominguez-Cano E, Voelkel NF and Bogaard HJ: Treatment for pulmonary arterial hypertension-associated right ventricular dysfunction. Ann Am Thorac Soc 11: 1101-1115, 2014.

17. Zhang CL, Xie S, Qiao X, An YM, Zhang Y, Li L, Guo XB, Zhang FC and Wu LL: Plasma endothelin-1-related peptides as the prognostic biomarkers for heart failure: A PRISMA-compliant meta-analysis. Medicine (Baltimore) 96: e9342, 2017.

18. Agterof MJ, van Bladel ER, Schutgens REG, Snijder RJ, Tromp EAM, Prins MH and Biesma DH: Risk stratification of patients with pulmonary embolism based on pulse rate and D-dimer concentration. Thromb Haemost 102: 683-687, 2009.

19. Inoue K, Kodama T and Daida H: Pentraxin 3: A novel biomarker for inflammatory cardiovascular disease. Int J Vasc Med 2012: 657025, 2012.

20. Scholfield M, Schabath MB and Guglin M: Longitudinal trends, hemodynamic profiles, and prognostic value of abnormal liver function tests in patients with acute decompensated heart failure: An analysis of the ESCAPE trial. J Card Fail 20: 476-484, 2014. 
21. Zheng $\mathrm{H}, \mathrm{Li} \mathrm{Y}$ and Xie N: Association of serum total bilirubin levels with diastolic dysfunction in heart failure with preserved ejection fraction. Biol Res 47: 7, 2014.

22. Altay $\mathrm{H}$ and Colkesen Y: Parathyroid hormone and heart failure: Novel biomarker strategy. Endocr Metab Immune Disord Drug Targets 13: 100-104, 2013.

23. Ulu SM, Ulaslı A, Yaman F, Yaman G, Ozkececi G and Yuksel S: The relationship between vitamin D and PTH levels and cardiovascular risk in the elderly hypertensives. Clin Exp Hypertens 36: 52-57, 2014.

24. Demir M, Günay T, Özmen G and Melek M: Relationship between vitamin $\mathrm{D}$ deficiency and nondipper hypertension. Clin Exp Hypertens 35: 45-49, 2013.

25. Soares AA, Freitas WM, Japiassú AV, Quaglia LA, Santos SN Pereira AC, Nadruz Junior W and Sposito AC: Enhanced parathyroid hormone levels are associated with left ventricle hypertrophy in very elderly men and women. J Am Soc Hypertens 9: 697-704, 2015.

26. Bosworth C, Sachs MC, Duprez D, Hoofnagle AN, Ix JH Jacobs DR Jr, Peralta CA, Siscovick DS, Kestenbaum B and de Boer IH: Parathyroid hormone and arterial dysfunction in the multi-ethnic study of atherosclerosis. Clin Endocrinol (Oxf) 79: 429-436, 2013

27. Wu GY, Xu BD, Wu T, Wang XY, Wang TX, Zhang X, Wang X, Xia Y and Zong GJ: Correlation between serum parathyroid hormone levels and coronary artery calcification in patients without renal failure. Biomed Rep 5: 601-606, 2016.

28. Klarić D, Klarić V and Kristić I: Cardiac valves calcifications in dialysis patients. Acta Med Croatica 65 (Suppl 3): 11-13, 2011 (In Croatian).

29. Sugimoto T, Dohi K, Onishi K, Watanabe K, Sato Y, Sugiura E, Nakamori S, Nakajima H, Nakamura M and Ito M: Interrelationship between haemodynamic state and serum intact parathyroid hormone levels in patients with chronic heart failure. Heart 99: 111-115, 2013.

30. Gaynor SL, Maniar HS, Bloch JB, Steendijk P and Moon MR: Right atrial and ventricular adaptation to chronic right ventricular pressure overload. Circulation 112 (Suppl): I212-I218, 2005.

31. Law PH, Sun Y, Bhattacharya SK, Chhokar VS and Weber KT: Diuretics and bone loss in rats with aldosteronism. J Am Coll Cardiol 46: 142-146, 2005.

32. Khouzam RN, Dishmon DA, Farah V, Flax SD, Carbone LD and Weber KT: Secondary hyperparathyroidism in patients with untreated and treated congestive heart failure. Am J Med Sci 331: $30-34,2006$

33. Goodwin KD, Sun Y, Weber KT, Bhattacharya SK, Ahokas RA and Gerling IC: Preventing oxidative stress in rats with aldosteronism by calcitriol and dietary calcium and magnesium supplements. Am J Med Sci 332: 73-78, 2006.

34. Laguardia SP, Dockery BK, Bhattacharya SK, Nelson MD, Carbone LD and Weber KT: Secondary hyperparathyroidism and hypovitaminosis D in African-Americans with decompensated heart failure. Am J Med Sci 332: 112-118, 2006.

35. Yano S, Macleod RJ, Chattopadhyay N, et al: Calcium-sensing receptor activation stimulates parathyroid hormone-related protein secretion in prostate cancer cells: Role of epidermal growth factor receptor transactivation. Bone 35: 664-672, 2004.

36. Brooks H, Kirk HS, Vokonas PS, Urschel CW and SonnenblickEH Performance of the right ventricle under stress: relation to right coronary flow. J Clin Invest 50: 2176-2183, 1971.
37. Berthelot E, Bauer F, Eicher JC, Flécher E, Gellen B, Guihaire J, Guijarro D, Roul G, Salvat M, Tribouilloy C, et al: Pulmonary hypertension in chronic heart failure: Definitions, advances, and unanswered issues. ESC Heart Fail 5: 755-763, 2018.

38. MeyerR,Schreckenberg R, Kretschmer F, Bittig A, Conzelmann C, Grohé $\mathrm{C}$ and Schlüter KD: Parathyroid hormone-related protein (PTHrP) signal cascade modulates myocardial dysfunction in the pressure overloaded heart. Eur J Heart Fail 9: 1156-1162, 2007.

39. Cardiovascular disease branch of China medical association, editorial committee of China journal of cardiovascular disease: Guide for diagnosis and treatment of chronic heart failure. Zhonghua Xin Xue Guan Bing Za Zhi 35: 1076-1095, 2007 (In Chinese).

40. Zhao G, Wu L, Liu Y, Gao L, Chen Y, Yao R and Zhang Y: Rosuvastatin reduces the recurrence rate following catheter ablation for atrial fibrillation in patients with heart failure. Biomed Rep 6: 346-352, 2017.

41. Yang GH, Ma JM, Liu N and Zhou LN: Smoking and passive smoking in Chinese, 2002. Zhonghua Liu Xing Bing Xue Za Zhi 26: 77-83, 2005 (In Chinese).

42. Li Y, Zhang M, Jiang Y, Deng Q, Zhao Y, Huang Z, Zeng X and Wang L: Drinking behaviors and patterns among floating population aged 18-59 years old in China, 2012. Zhonghua Liu Xing Bing Xue Za Zhi 35: 1186-1191, 2014 (In Chinese).

43. Lang RM, Badano LP, Mor-Avi V, Afilalo J, Armstrong A, Ernande L, Flachskampf FA, Foster E, Goldstein SA, Kuznetsova T, et al: Recommendations for cardiac chamber quantification by echocardiography in adults: An update from the American Society of Echocardiography and the European Association of Cardiovascular Imaging. J Am Soc Echocardiogr 28: 1-39.e14, 2015.

44. Matsubara J, Sugiyama S, Nozaki T, Sugamura K, Konishi M, Ohba K, Matsuzawa Y, Akiyama E, Yamamoto E, Sakamoto $\mathrm{K}$, et al: Pentraxin 3 is a new inflammatory marker correlated with left ventricular diastolic dysfunction and heart failure with normal ejection fraction. J Am Coll Cardiol 57: 861-869, 2011.

45. Bosselmann H, Tonder N, Sölétormos G, Gaborit F, Rossing K, Iversen K, Goetze JP, Gustafsson F and Schou M: Influence of renal impairment on aldosterone status, calcium metabolism, and vasopressin activity in outpatients with systolic heart failure. ESC Heart Fail 4: 554-562, 2017.

46. Sugimoto T, Tanigawa T, Onishi K, Fujimoto N, Matsuda A, Nakamori S, Matsuoka K, Nakamura T, Koji T and Ito M: Serum intact parathyroid hormone levels predict hospitalisation for heart failure. Heart 95: 395-398, 2009.

47. Susan T: Haden, Edward M. Brown, Shelley Hurwitz, Jennifer Scott, Ghada El-Hajj Fuleihan. The effects of age and gender on parathyroid hormone dynamics. Clin Endocrinol (Oxf) 52: 329-338, 2000.

48. Lalande S and Johnson BD: Diastolic dysfunction: A link between hypertension and heart failure. Drugs Today (Barc) 44: 503-513, 2008

49. Pepe J, Curione M, Morelli S, Colotto M, Varrenti M, Castro C, D'Angelo A, Cipriani C, Piemonte S, Romagnoli E, et al: Arrhythmias in primary hyperparathyroidism evaluated by exercise test. Eur J Clin Invest 43: 208-214, 2013.

50. Denham NC, Pearman CM, Caldwell JL, Madders GWP, Eisner DA, Trafford AW and Dibb KM: Calcium in the Pathophysiology of Atrial Fibrillation and Heart Failure. Front Physiol 9: 1380, 2018. 